\title{
Fused filament fabrication of commercial conductive filaments: experimental study on the process parameters aimed at the minimization, repeatability and thermal characterization of electrical resistance
}

\author{
Gianni Stano ${ }^{1}$ (D) - Attilio Di Nisio ${ }^{2} \cdot$ Anna Maria Lanzolla $^{2} \cdot$ Mattia Ragolia $^{2} \cdot$ Gianluca Percoco $^{1}$
}

Received: 23 June 2020 / Accepted: 26 October 2020 / Published online: 5 November 2020

(C) The Author(s) 2020

\begin{abstract}
Nowadays, a challenging scenario involving additive manufacturing (AM), or 3D printing, relates to concerns on the manufacturing of electronic devices. In particular, the possibility of using fused filament fabrication (FFF) technology, which is well known for being very widespread and inexpensive, to fabricate structures with embedded sensing elements, is really appealing. Several researchers in this field have highlighted the high electrical resistance values and variability in 3D-printed strain sensors made via FFF. It is important to find a way to minimize the electrical resistance and variability among strain sensors printed under the same conditions for several reasons, such as reducing the measurement noise and better balancing four 3D-printed strain gauges connected to form a Wheatstone bridge to obtain better measurements. In this study, a design of experiment (DoE) on 3Dprinted strain gauges, studying the relevance of printing and design parameters, was performed. Three different commercial conductive materials were analyzed, including a total of 105 printed samples. The output of this study is a combination of parameters which allow both the electrical resistance and variability to be minimized; in particular, it was discovered that the "welding effect" due to the layer height and printing orientation is responsible for high values of resistance and variability. After the optimization of printing and design parameters, further experiments were performed to characterize the sensitivity of each specimen to mechanical and thermal stresses, highlighting an interesting aspect. A sensible variation of the electrical resistance at room temperature was observed, even if no stress was applied to the specimen, suggesting the potential of exploiting these materials for the 3D printing of highly sensitive temperature sensors.
\end{abstract}

Keywords Additive manufacturing $\cdot 3 \mathrm{D}$ printed electronics $\cdot$ Strain gauge $\cdot$ Conductive filaments $\cdot$ Fused filament fabrication

\section{Introduction}

Additive manufacturing (AM), also known as threedimensional (3D) printing, is a new fabrication approach based on the idea of manufacturing objects layer by layer. The aerospace field has benefited from AM. Generally, powder bed fusion (PBF) and direct energy deposition (DED) are the AM categories mostly involved in this field [1], which are

Gianni Stano

gianni.stano@poliba.it

1 Department of Mechanics, Mathematics and Management, Polytechnic of Bari, Via E. Orabona 4, 70125 Bari, Italy

2 Department of Electrical and Information Engineering, Polytechnic of Bari, Via E. Orabona 4, 70125 Bari, Italy used for the fabrication of complex geometries and for repairing critical components [2]. Nowadays, the improvement of an advanced algorithm in laser cladding technology (applicable both to direct manufacturing and to repair) used for the homogenous material deposition of disk blades [3], the development of a new methodology to inspect the reliability of AM components based on stochastic defect-propagation analysis [4], and advances in fiber-reinforced polymer composites and aluminum alloy lattice structures $[5,6]$, paves the way for a wider use of AM technologies in the aerospace industry. AM has been used for monitoring structures by embedding sensing elements [7], which can compete with other approaches based on time-domain reflectometry [8]. Recently, beyond the wide exploitation of AM in the aerospace field, a growing interest in electronics manufactured by AM technologies has emerged [9], both in the field of active electronic 
components and passive ones [10,11]. They have also proven useful for the optimization of microbial fuel cells, finding possible applications in sustainable energy production as well as microbial corrosion assessment [12]. Proof of the close link between AM and electronics has been provided by the birth of several customized 3D printers, such as the multi-process 3D printer developed by MacDonald et al. [13] and the multimaterial 3D printer based on three syringes designed by Emon et al. [14], which allow the manufacturing of electronic devices using non-conventional manufacturing approaches. In the electronic field, it is possible to split the classic fabrication methods into two classes: (i) subtractive technologies, such as lithography, and (ii) 2D printing techniques, which include flexographic, offset, gravure, and screen printing [15]. In accordance with [16], it is possible to define three methods to combine dielectric and conductive parts involving AM technologies in the manufacturing process: the hybrid approach, conductor infusion, and multi-material printing. In particular, regarding the hybrid approach, it has been proven that it is possible to generate several advantages from a specific method based on temporary pausing the AM process, generally fused filament fabrication (FFF), the integration of sensitive elements (e.g., copper wires) and resuming the 3D printing process [17-19]. 3D-printed sensors can be divided into three classes: physical, chemical, and bio sensor classes [20]. The physical sensor sub-class is very challenging for researchers and industries in terms of strain sensors. 3D-printed strain sensors are usually piezoresistive sensors which base their operating principle on the piezoresistive effect, according to which, when the piezoresistive material is deformed upon external stimuli, it changes its electrical resistance value. It is well known that the electrical resistance $R$ can be calculated as $R=\rho(l / A)$, where $\rho$ is the material resistivity and $l / A$ is the ratio between the piezoresistive material length and its transverse section surface. As a matter of fact, when an external force is applied, the geometry of the piezoresistive material changes, involving alteration of the ratio $l / A$, which leads to a change in the resistance value. Moreover, for several piezoresistive materials, in conjunction with the ratio $l / A$, the resistivity $\rho$ also changes [21]. Wearable and stretchable electronics is a growing field in which strain sensors play a fundamental role; there are several applications related to this field, such as health-monitoring, human motion detection, human-machine interfaces, and soft robotics [22]. An example of an additively manufactured wearable strain sensor for detecting joint motions during finger bending has been provided by Wang et al. [23], who used a 3D printer machine to extrude a stretchable and conductive hydrogel. Another milestone in this field is the work of Muth et al. [24], in which they used AM as follows: by means of a nozzle, they deposited a conductive viscoelastic ink within an elastomeric reservoir in order to create a wearable and stretchable smart glove able to detect motions through electrical resistance changes.
A metal paste, with electrical properties comparable to those of pure liquid metal, which can be directly 3D-printed using a dispenser equipped with a $10 \mathrm{cc}$ syringe barrel, has been created [25]; it enables the layer-by-layer printing of vertical structures through continuous extrusion.

Among the AM technologies based upon the material extrusion working principle, without a doubt, used filament fabrication (FFF), also known as fused deposition modeling (FDM), which is the trademark name given by Stratasys, Inc., is the most common and inexpensive one. Several studies have been conducted not only for relating the main process parameters to mechanical properties of the FFF manufactured parts $[26,27]$ but also for improving surface finishing [28]. Using dual extruder FFF 3D printers, it is possible to embed sensitive elements into non-sensitive ones in a single-step manufacturing cycle [29]. Using Bridgman model, a method to identify piezoresistive coefficients of sensors manufactured via FFF was successfully developed [30]. Two features which affect the sensing elements (generally, strain sensors) manufactured via FFF technology, with both commercial conductive filaments [31] and customized filaments created in situ [32-34], are (i) the high electrical resistance value of 3D-printed sensing elements (in [35], a novel method based on flash lamp ablation to reduce it, is presented) and (ii) the difficulties in manufacturing more identical sensing elements with the same, or somewhat comparable, electrical resistance values. In this study, working on 3D-printed strain gauges, the most common and widely used strain sensor, printing and design parameters have been investigated in order to find a parameter combination which allows the final electrical resistance to be minimized and the variability among identical strain gauges in terms of the electrical resistance to be reduced. In particular, three different commercial conductive filaments have been analyzed in terms of their performance. First of all, a factorial plan $2^{3}$ on printing parameters was constructed and afterwards, keeping the best printing parameters identified unchanged, a new factorial plan $2^{2}$ was developed to identify the best strain gauge geometry, in order to minimize the electrical resistance and variability. The aims of the minimization and uniformization of the electrical resistance are as follows (i) to try to decrease the electrical resistance to reduce the noise during measurements; (ii) to achieve a low resistance value in order to use 3D-printed conductive traces to exploit the Joule effect, with the goal of heating polymers characterized by the shape memory effect [36] from the perspective of new emerging 4D printing [37]; (iii) to reduce the variability among resistance values of the identical (both from a design and manufacturing process point of view) strain gauges, to pave the way for the mass production of sensors manufactured by inexpensive FFF technology; and (iv) to reduce the variability in order to better balance four 3D-printed strain gauges connected to form a Wheatstone bridge to obtain better measurements. 
After finding the best set of parameters and based on the experimental findings, a further analysis was performed to understand the correlation among resistance variation in strain gauges and environmental temperature change. This study has produced evidence of the relevant thermal effects on 3Dprinted strain gauges, suggesting a new possible application field for conductive filaments - the fabrication of 3D-printed temperature sensors.

\section{Design of experiment (DoE) for resistance minimization and uniformization}

\subsection{Materials, machines, and methods}

Three different commercial conductive filaments were studied in this investigation: (i) AlfaOhm, a polylactic acid (PLA)based filament doped with carbon black and carbon nanotubes (CNT), which make it conductive, developed by LATI and FiloAlfa; it is characterized by a resistivity of $15 \Omega \cdot \mathrm{cm}$ along the layers and $20 \Omega \cdot \mathrm{cm}$ perpendicular to the layers; (ii) Fabbrix CNT (henceforth called CNT), a PLA-based filament doped with carbon nanotubes (CNTs) and developed by Fabbrix, with a surface electrical resistance of $10 \Omega$, tested in accordance with ISO D257; and (iii) Ninjatek Eel (henceforth called Eel), a flexible conductive filament, consists of thermoplastic polyurethane (TPU) doped with carbon-black, produced by Ninjatek with a hardness of $90 \mathrm{~A}$, tensile strength of $12 \mathrm{MPa}$, elongation at strength of $355 \%$, and surface electrical resistance of $1.5 \cdot 10^{3}$, in accordance with ANSI/ESD STM 11.1. All data on the mechanical and electrical properties were taken from filament data sheets. For AlfaOhm and CNT, the available filament diameter on the market is $2.85 \mathrm{~mm}$, while for Eel, it is $1.75 \mathrm{~mm}$. For this reason, two different dual extruder FFF printers were used: Ultimaker $\mathrm{S}^{5}$ was used for 2.85-mm filaments, while Raise Pro2 was employed for 1.75$\mathrm{mm}$ filaments. Another notable difference between the two 3D printers is the different feeder (the mechanical system which pushes the filament to the extruder) locations: while for Ultimaker $\mathrm{S}^{5}$, it is located at the bottom of the printer (called the bowden system) and pushes the filament through a Teflon tube up to the extruder, for Raise Pro2, the feeder is joined to the extruder (called direct system) so that the filament path employed to reach the nozzle is the minimum. The different feeder positions affect printing parameters such as the printing speed (3D printers with the Bowden system are lighter and allow fast extruder movements) and retraction distance (for printers equipped by the direct system, low values of retraction are required).

The open-source software Ultimaker Cura 4.4 was used to communicate with Ultimaker $\mathrm{S}^{5}$ and set the printing parameters, while ideaMaker 3.4.2 was used for Raise Pro2. Two commercial thermoplastic polyurethane (TPU) filaments were used as non-sensitive elements: for Ultimaker $\mathrm{S}^{5}$, TPU $95 \mathrm{~A}$ developed by Ultimaker Itd was used, while for Raise Pro2, TPU 90 A produced by Fabbrix was chosen. Therefore, the whole sensor was composed of a dielectric part in TPU ( 95 or $90 \mathrm{~A}$, in accordance with the 3D printer used), equipped with an M4 hole to easily connect the sensor to a support framework for future characterization tests and a sensitive part composed of a strain gauge printed with AlfaOhm, CNT, or Eel filaments. In Fig. 1(a), the structure of the whole sensor is shown.

To minimize and equalize the electrical resistance in 3Dprinted strain gauges, the following method was used: printing process parameters and design parameters were split and separately investigated. First of all, strain gauges with fixed design parameters were manufactured by changing three different printing parameters in accordance with a $2^{3}$ factorial plan, with three replications; from this phase, a combination of three printing parameters which ensured minimization and uniformization of the electrical resistance stood out. Afterwards, keeping the best printing parameter combination identified fixed, two different design parameters were studied following a $2^{2}$ factorial plan with three replications. The final output of the experimental phase was a combination of process and design parameters which guaranteed the achievement of the desired objectives. It was possible to perform two consecutive factorial plans, $2^{3}$ and $2^{2}$, by splitting printing and design parameters, rather than a unique $2^{5}$ one only, because printing and design parameters are independent of each other; indeed, printing parameters do not affect design ones and vice versa. Arbitrarily, it was decided that the study would start with the printing parameter investigation (with the design
Fig. 1 Sensor: (a) Computeraided design (CAD) of the sensor composed of a strain gauge (black) and non-sensitive part (gray) and (b) manufactured sensors with electrical wires welded to the pads
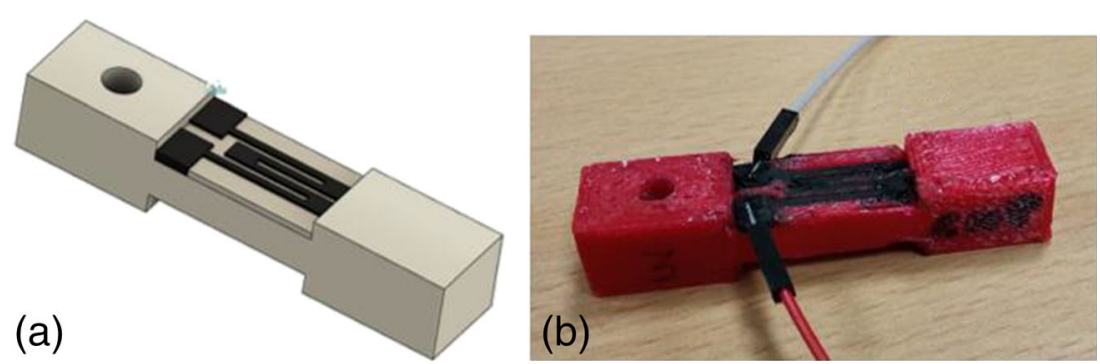
parameters kept unchanged), and after this, it would be switched to a design parameter examination (with the best combination of printing parameters found in the previous phase kept fixed), but vice versa would have led to the same result.

\subsection{Printing parameter investigation}

In this section, an investigation on how the chosen printing parameters affect the electrical resistance and the variability in $3 \mathrm{D}$-printed strain gauges is reported. The factorial plan $2^{3}$, with three replications for each combination, was performed. The strain gauge geometry on which to vary the printing parameters was fixed; in particular, it was characterized by a number of tracks of 4 and an active length of $9 \mathrm{~mm}$. In other terms, all experiments were performed by keeping constant $\mathrm{D}$ and E parameters at the low level of -1 (see Section 2.3 to better understand this point).

The printing parameters analyzed in this study are the layer height, line width, and printing orientation.

The layer height is the height of the extruded filament, and it affects the total number of layers which will be printed (increasing the layer height provides a reduction of the total number of printed layers). In this study, this parameter is indicated with the letter A and two levels (respectively -1 and + 1) corresponding to height values of 0.2 and $0.3 \mathrm{~mm}$.
The line width feature is the width of the extruded filament. It depends on the nozzle diameter and should approximately range from $-20 \%$ of the nozzle diameter up to $+20 \%$. The line width affects the number of adjacent extruded filament lines (when increasing the line width value, the number of adjacent lines will be reduced). This parameter is indicated with the letter B, and the two levels, -1 and +1 , respectively, are $0.33 \mathrm{~mm}$, which is equal to three adjacent extruded lines, and $0.5 \mathrm{~mm}$, which is equal to two adjacent extruded lines.

The layer height and line width parameters are illustrated in Fig. 2(a).

Regarding the latter printing parameter, namely, the printing orientation, it refers to way in which the strain gauge is orientated relative to the build plate. This parameter is indicated with the letter $\mathrm{C}$, and the low level, -1 , refers to the strain gauge parallel to the build plate, while the high level, +1 , refers to the strain gauge perpendicular to the build plate (Fig. 2(b) and (c)).

In Table 1, the printing parameter factors and the respective levels are summarized.

The process parameters, except for the layer height, line width, and printing orientation (varied in accordance with the $2^{3}$ plan), were kept fixed for each sensor specimen during the experiments. They, starting from the suggested values provided by the filament suppliers, were changed until the best process values for each filament, both conductive than

(a)
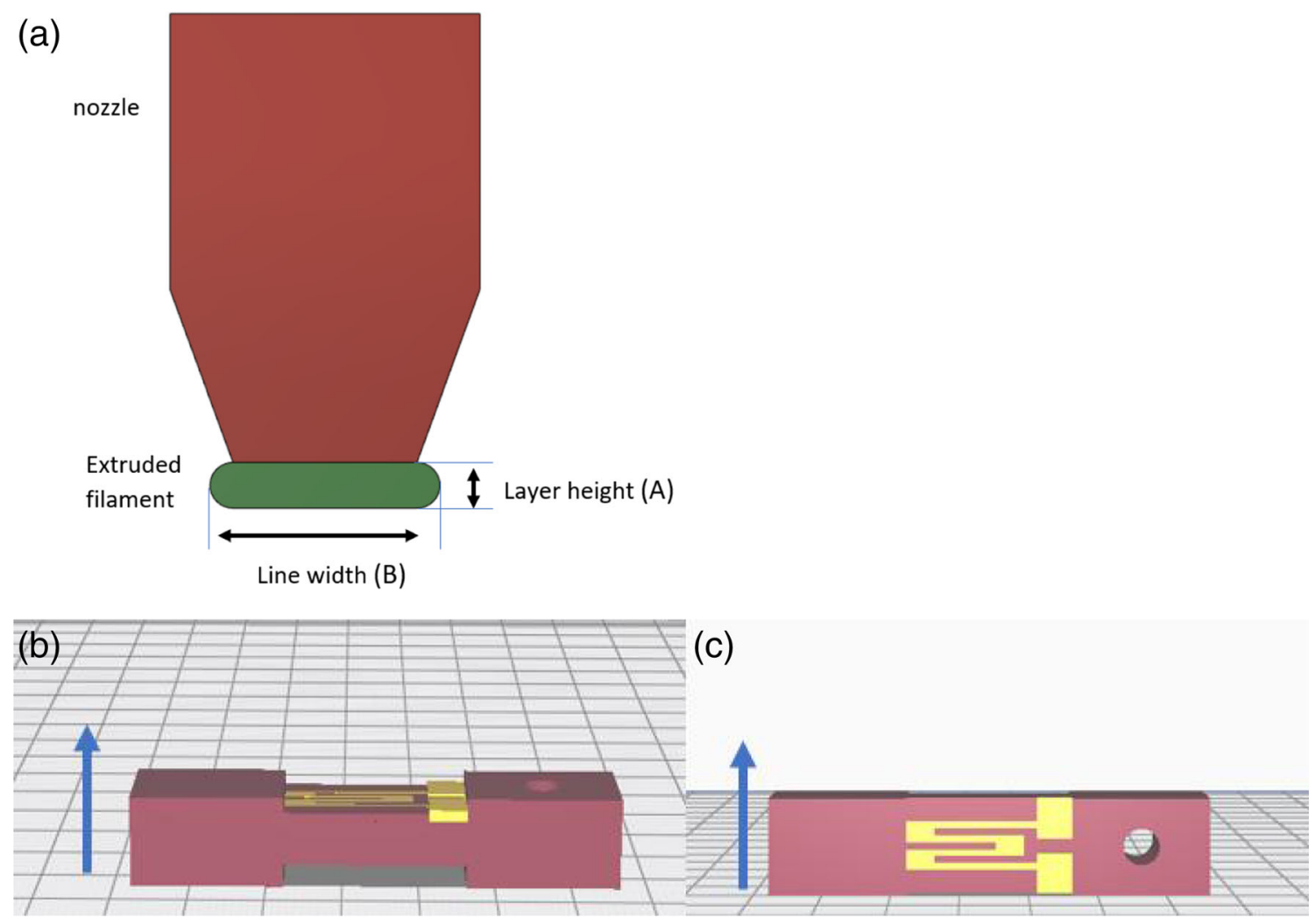

Fig. 2 Printing parameters: (a) 2D front view of nozzle-extruded filament: layer height and line width are shown, (b) strain gauge parallel to the build plate, and (c) strain gauge perpendicular to the build plate 
Table 1 Factor levels

\begin{tabular}{lll}
\hline Factor & \multicolumn{2}{l}{ Level } \\
\cline { 2 - 3 } & -1 & +1 \\
\hline A (layer height) & $0.2 \mathrm{~mm}$ & $0.3 \mathrm{~mm}$ \\
B (line width) & $0.33 \mathrm{~mm}$ & $0.5 \mathrm{~mm}$ \\
C (printing orientation) & parallel & perpendicular \\
\hline
\end{tabular}

non-conductive, had been found using a trial-and-error approach. The fixed printing parameters set during all the experiments are shown in Table 2. In particular, the identical process parameters set for each filament were as follows: (i) nozzle diameter of $0.4 \mathrm{~mm}$ (ii) build plate adhesion type set as brim; iii) infill pattern set as lines; and (iv) infill density set as $100 \%$. For the printing parameter choice, two major differences among filaments extruded by means of the Bowden machine (Ultimaker $\mathrm{S}^{5}$ ) and direct one (Raise Pro2) stand out: (i) the Bowden machine, because of its architecture, with the feeder located at the bottom of the 3D printer, is lighter than the direct one and for this reason, higher printing speed values were set, and (ii) in the direct machine, the path of the filament from the feeder to the nozzle is very short compared with that of the Bowden machine, and for this reason, for TPU 90 A (extruded with Raise Pro2), the retraction distance value is almost half that of TPU $95 \mathrm{~A}$ (extruded with Ultimaker $\mathrm{S}^{5}$ ).

Another considerable discrepancy is the different value set for the "retraction" parameter for conductive filaments; this choice is not linked to the kind of 3D printer used, but depends on the different chemical compositions underlying conductive filaments. As a matter of fact, AlfaOhm and CNT are PLAbased filaments doped with conductive elements, which increase the brittleness of the filament, while Eel is a flexible conductive filament (TPU-based) characterized by a nonbrittle behavior. Experimentally, it has been proved that for PLA-based conductive filaments, there is a high probability of filament breakage between the driving gears which push the filament to the nozzle, when retraction is enabled. On the other hand, Eel does not show any breakage issues when the retraction is enabled because of its flexible and non-brittle nature. Additionally, to reduce cross-contamination issues at the interface between conductive and non-conductive material, the prime tower parameter was enabled for all specimens. After sensor manufacturing, electrical wires were welded at the temperature of $350{ }^{\circ} \mathrm{C}$ to each pad of strain gauges, in order to use benchtop multimeters for electrical measurements (see Fig. 1(b)).

In Tables 3, 4, and 5, the factorial plan $2^{3}$ for the three conductive filaments is shown. The mean $\mu$ and standard deviation $\sigma$ were calculated as follows:

$\mu_{j}=\sum_{n=1}^{m} r_{j ; n}$,

$\sigma_{j}=\sqrt{\frac{1}{m-1} \sum_{n=1}^{m}\left(\mu_{j}-r_{j ; n}\right)^{2}}$,

where $j$ indicates the $j$ th combination and $n$ is the replication number with $n=1, \ldots, m$ and $m=3$, so $r_{j ; n}$ indicates the electrical resistance value associated with the $j$ th combination and $n$th replication.

In Fig. 3, Pareto charts of the standardized effects for each conductive material are reported, while in Table 6 , the effects (non-standardized) and respective $p$ values $(\alpha=0,05)$ for each conductive material factor and factor combination are listed.

From the results of the factorial plan, several considerations can be drawn:

1) The growth of the electrical resistance affects the variability among the three strain gauges belonging to the same combination. The variability can be measured as the standard deviation of the three electrical resistance values achieved for the same combination (see Eq. (2)). In particular, there is a positive correlation among resistance values and variability; indeed, when the mean electrical resistance (measured as shown in Eq. (1)) increases, then the variability also increases. This correlation plays a key role in 3D-printed sensors because future studies on parameter optimization will lead to several simultaneous benefits due to resistance and variability minimization,
Table 2 Fixed printing parameters for each filament

\begin{tabular}{llllll}
\hline Parameter & AlfaOhm & CNT & Eel & TPU 95 A & TPU 90 A \\
\hline Temperature $\left(^{\circ}\right)$ & 220 & 225 & 235 & 223 & 230 \\
Printing speed $(\mathrm{mm} / \mathrm{s})$ & 20 & 25 & 22 & 40 & 25 \\
Flow $(\%)$ & 120 & 120 & 130 & 106 & 106 \\
Retraction & Disabled & Disabled & Enabled & Enabled & Enabled \\
Retraction distance $(\mathrm{mm})$ & - & - & 4 & 8 & 4,5 \\
\hline
\end{tabular}


Table 3 AlfaOhm printing parameter factorial plan

\begin{tabular}{|c|c|c|c|c|c|c|c|c|}
\hline \multirow[t]{2}{*}{ Combination } & \multirow[t]{2}{*}{ A } & \multirow[t]{2}{*}{$\mathrm{B}$} & \multirow[t]{2}{*}{$\mathrm{C}$} & \multicolumn{3}{|c|}{ Replication $(k \Omega)$} & \multirow{2}{*}{$\begin{array}{l}\mu \\
(k \Omega)\end{array}$} & \multirow{2}{*}{$\begin{array}{l}\sigma \\
(k \Omega)\end{array}$} \\
\hline & & & & $n_{1}$ & $n_{2}$ & $n_{3}$ & & \\
\hline (1) & -1 & -1 & -1 & 5.1 & 3.9 & 2.9 & 4 & 1.1 \\
\hline $\mathrm{a}$ & +1 & -1 & -1 & 2.5 & 2.2 & 3.1 & 2.6 & 0.46 \\
\hline $\mathrm{b}$ & -1 & +1 & -1 & 3.4 & 5.2 & 3 & 3.9 & 1.2 \\
\hline$a b$ & +1 & +1 & -1 & 2.8 & 2.4 & 2.3 & 2.5 & 0.26 \\
\hline $\mathrm{c}$ & -1 & -1 & +1 & 3.8 & 6.2 & 4.4 & 4.8 & 1.2 \\
\hline ac & +1 & -1 & +1 & 2.6 & 3.4 & 2.5 & 2.8 & 0.49 \\
\hline $\mathrm{bc}$ & -1 & +1 & +1 & 3.4 & 6.1 & 4.5 & 4.7 & 1.3 \\
\hline$a b c$ & +1 & +1 & +1 & 2.6 & 3.2 & 2.5 & 2.8 & 0.38 \\
\hline
\end{tabular}

such as noise reduction during measurements or the possibility to connect more strain gauges in Wheatstone bridge configurations to obtain better measurements from several points of view. For AlfaOhm and CNT, the behavior in terms of the standard deviation vs. mean electrical resistance is very similar; indeed, for the four lower resistance values (combinations: $a, a b, a c$, and $a b c$ ), the standard deviation value is less than $0.5 \mathrm{k} \Omega$, while for large resistance values, the standard deviation increases, reaching the maximum values of 1.3 and $1.2 \mathrm{k} \Omega$ for AlfaOhm and CNT, respectively. The Eel behavior is slightly different: in terms of the lowest value of resistance (combination $a b$ ), the standard deviation is $1.3 \mathrm{k} \Omega$, while for the other three lowest electrical resistance values, the standard deviation is less than $0.5 \mathrm{k} \Omega$, as for AlfaOhm and CNT. This unusual behavior can be attributed to a cross-contamination problem, which is typical for multi-material printing. In the opinion of the authors, it is very probable that, during the printing, on a

Table 4 CNT printing parameter factorial plan

\begin{tabular}{|c|c|c|c|c|c|c|c|c|}
\hline \multicolumn{9}{|l|}{ CNT } \\
\hline \multirow[t]{2}{*}{ Combination } & \multirow[t]{2}{*}{ A } & \multirow[t]{2}{*}{ B } & \multirow[t]{2}{*}{$\mathrm{C}$} & \multicolumn{3}{|c|}{ Replication $(k \Omega)$} & \multirow{2}{*}{$\begin{array}{l}\mu \\
(k \Omega)\end{array}$} & \multirow{2}{*}{$\begin{array}{l}\sigma \\
(k \Omega\end{array}$} \\
\hline & & & & $n_{1}$ & $n_{2}$ & $n_{3}$ & & \\
\hline (1) & -1 & -1 & -1 & 5.4 & 4. & 3.6 & 4.3 & 0.9 \\
\hline $\mathrm{a}$ & +1 & -1 & -1 & 2.4 & 2.4 & 2.5 & 2.4 & 0.1 \\
\hline $\mathrm{b}$ & -1 & +1 & -1 & 4 & 3.5 & 4.9 & 4.1 & 0.7 \\
\hline$a b$ & +1 & +1 & -1 & 1.9 & 2.2 & 2.3 & 2.1 & 0.2 \\
\hline $\mathrm{c}$ & -1 & -1 & +1 & 4.1 & 6.5 & 5.1 & 5.2 & 1.2 \\
\hline $\mathrm{ac}$ & +1 & -1 & +1 & 2.6 & 2.4 & 2.8 & 2.6 & 0.2 \\
\hline $\mathrm{bc}$ & -1 & +1 & +1 & 6 & 4.6 & 4.9 & 5.2 & 0.7 \\
\hline$a b c$ & +1 & +1 & +1 & 2.7 & 2 & 2.6 & 2.4 & 0.4 \\
\hline
\end{tabular}

Table 5 Eel printing parameter factorial plan

\begin{tabular}{|c|c|c|c|c|c|c|c|c|}
\hline \multirow[t]{2}{*}{ Combination } & \multirow[t]{2}{*}{$\mathrm{A}$} & \multirow[t]{2}{*}{ B } & \multirow[t]{2}{*}{$\mathrm{C}$} & \multicolumn{3}{|c|}{ Replication $(k \Omega)$} & \multirow{2}{*}{$\begin{array}{l}\mu \\
(k \Omega)\end{array}$} & \multirow{2}{*}{$\begin{array}{l}\sigma \\
(k \Omega\end{array}$} \\
\hline & & & & $n_{1}$ & $n_{2}$ & $n_{3}$ & & \\
\hline (1) & -1 & -1 & -1 & 11.3 & 7.2 & 8.3 & 8.9 & 2.1 \\
\hline a & +1 & -1 & -1 & 4.6 & 5.3 & 4.7 & 4.9 & 0.4 \\
\hline $\mathrm{b}$ & -1 & +1 & -1 & 10.4 & 8.4 & 7.1 & 8.6 & 1.7 \\
\hline$a b$ & +1 & +1 & -1 & 4.8 & 4.3 & 2.4 & 3.8 & 1.3 \\
\hline $\mathrm{c}$ & -1 & -1 & +1 & 13.2 & 8.1 & 9.7 & 10.3 & 2.6 \\
\hline $\mathrm{ac}$ & +1 & -1 & +1 & 5.0 & 5.6 & 5.7 & 5.4 & 0.4 \\
\hline $\mathrm{bc}$ & -1 & +1 & +1 & 7.4 & 9.3 & 12.9 & 9.9 & 2.8 \\
\hline$a b c$ & +1 & +1 & +1 & 5.5 & 4.8 & 5.2 & 5.2 & 0.4 \\
\hline
\end{tabular}

certain layer, a residue of TPU 90 A carried by the hot nozzle came into contact with the Eel track already deposited, reducing the electrical resistance of the strain gauge belonging to the $a b$ combination and third replication $(n=3)$. This would explain the significative difference in resistance values for the combination $a b$, where there is an anomalous value of $2.4 \mathrm{k} \Omega$, in contrast with 4.3 and $4.8 \mathrm{k} \Omega$. To demonstrate this theory, five other Eel samples were printed in accordance with process parameter levels of the combination $a b$, which resulted in a measured standard deviation of $0.34 \mathrm{k} \Omega$ and a mean resistance value of $4.7 \mathrm{k} \Omega$.

In Fig. 4, the values of standard deviation of the mean electrical resistance for each combination of the three conductive materials are reported:

2) The main parameter affecting the electrical resistance, for each conductive material, is the layer height: switching from a layer height of $0.2-0.3 \mathrm{~mm}$ resulted in a greater decrease in electrical resistance in comparison to changing other parameters. Therefore, the first parameter that should be set in order to reduce the resistance (and the variability) is the layer height; in this study, a nozzle diameter of 0.4 was used, which does not allow layer height values greater than $0.3 \mathrm{~mm}$, but using other diameter nozzles (e.g., $1 \mathrm{~mm}$ ), it should be possible to increase the layer height to $0.8 / 0.9 \mathrm{~mm}$, which would entail, in accordance with the results of this study, a further reduction of the electrical resistance and variability. A possible reason why the layer height affects the electrical resistance so much is as follows: when the filament is extruded and deposited by means of the nozzle, it has a quasielliptical shape, and when more layers are built on each other, voids, commonly referred to as air gaps in the literature, are generated among quasi-elliptical extruded filaments of layer $k$ and layer $k+1$ (Fig. 5). Voids involve a 

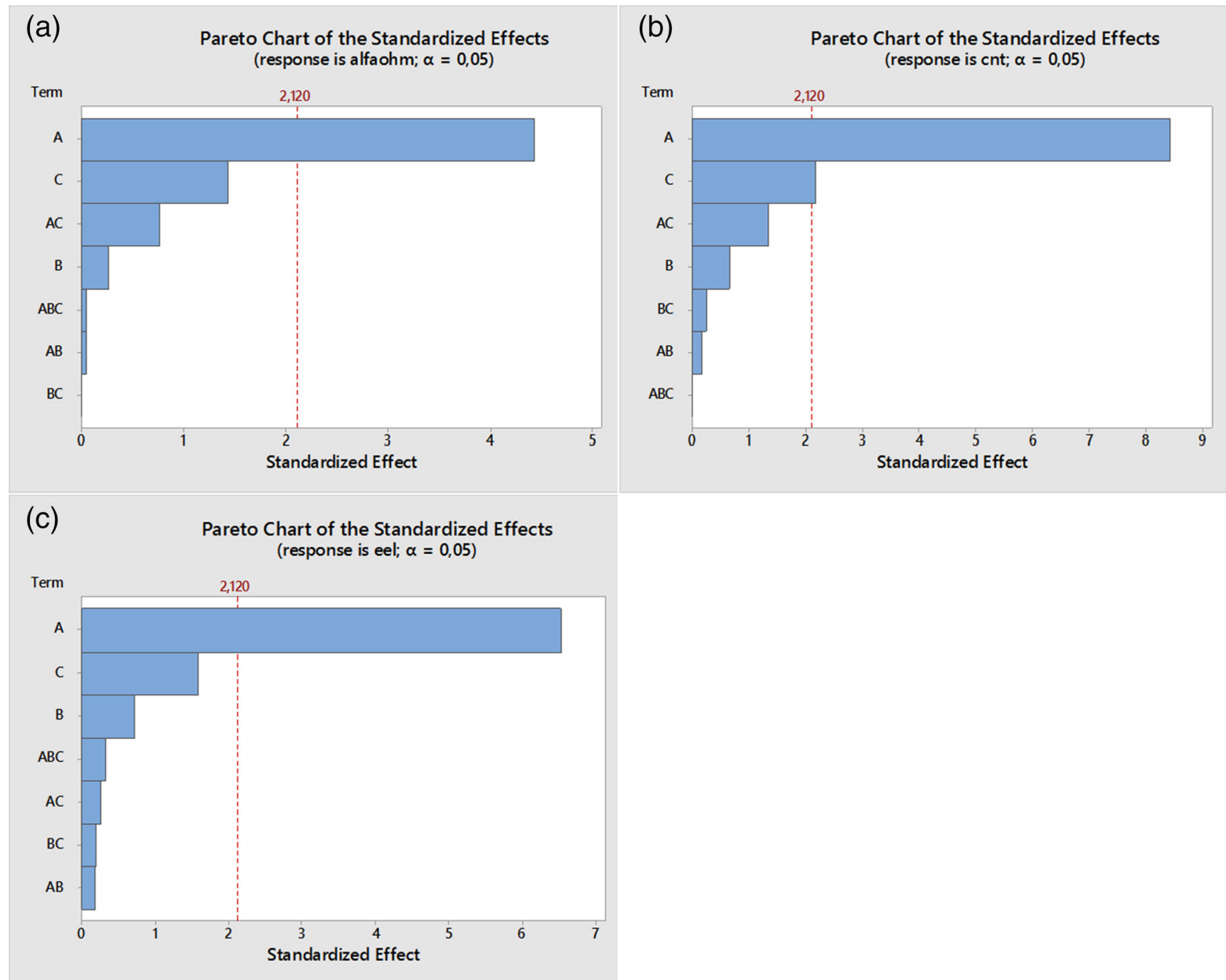

Fig. 3 Pareto charts of standardized effects: (a) AlfaOhm, (b) CNT, and (c) Eel

reduction of electrical resistance because there are small zones in which there is no contact among extruded conductive filaments of adjacent layers, and this phenomenon is named the "welding effect" by the authors. When increasing the layer height from 0.2 to $0.3 \mathrm{~mm}$, the total number of layers that will be built decreases (in the first

Table 6 Non-standardized effect and p value

\begin{tabular}{|c|c|c|c|c|c|c|}
\hline \multirow[t]{2}{*}{ Factor/factor combination } & \multicolumn{2}{|c|}{ AlfaOhm } & \multicolumn{2}{|l|}{ CNT } & \multicolumn{2}{|l|}{ Eel } \\
\hline & Effect & $p$ value & Effect & $p$ value & Effect & $p$ value \\
\hline A & -1.65 & 0 & -2.317 & 0 & -4.608 & 0 \\
\hline $\mathrm{B}$ & -0.1 & 0.792 & -0.183 & 0.514 & -0.508 & 0.482 \\
\hline $\mathrm{C}$ & 0.53 & 0.171 & 0.6 & 0.044 & 1.125 & 0.131 \\
\hline $\mathrm{A} * \mathrm{~B}$ & 0.017 & 0.965 & -0.05 & 0.858 & -0.125 & 0.862 \\
\hline $\mathrm{A}^{*} \mathrm{C}$ & -0.283 & 0.458 & -0.367 & 0.201 & -0.192 & 0.79 \\
\hline $\mathrm{B} * \mathrm{C}$ & 0 & 1 & 0.067 & 0.811 & 0.142 & 0.844 \\
\hline $\mathrm{A} * \mathrm{~B} * \mathrm{C}$ & 0.017 & 0.965 & 0 & 1 & 0.225 & 0.754 \\
\hline
\end{tabular}


Fig. 4 Standard deviation vs. mean electrical resistance

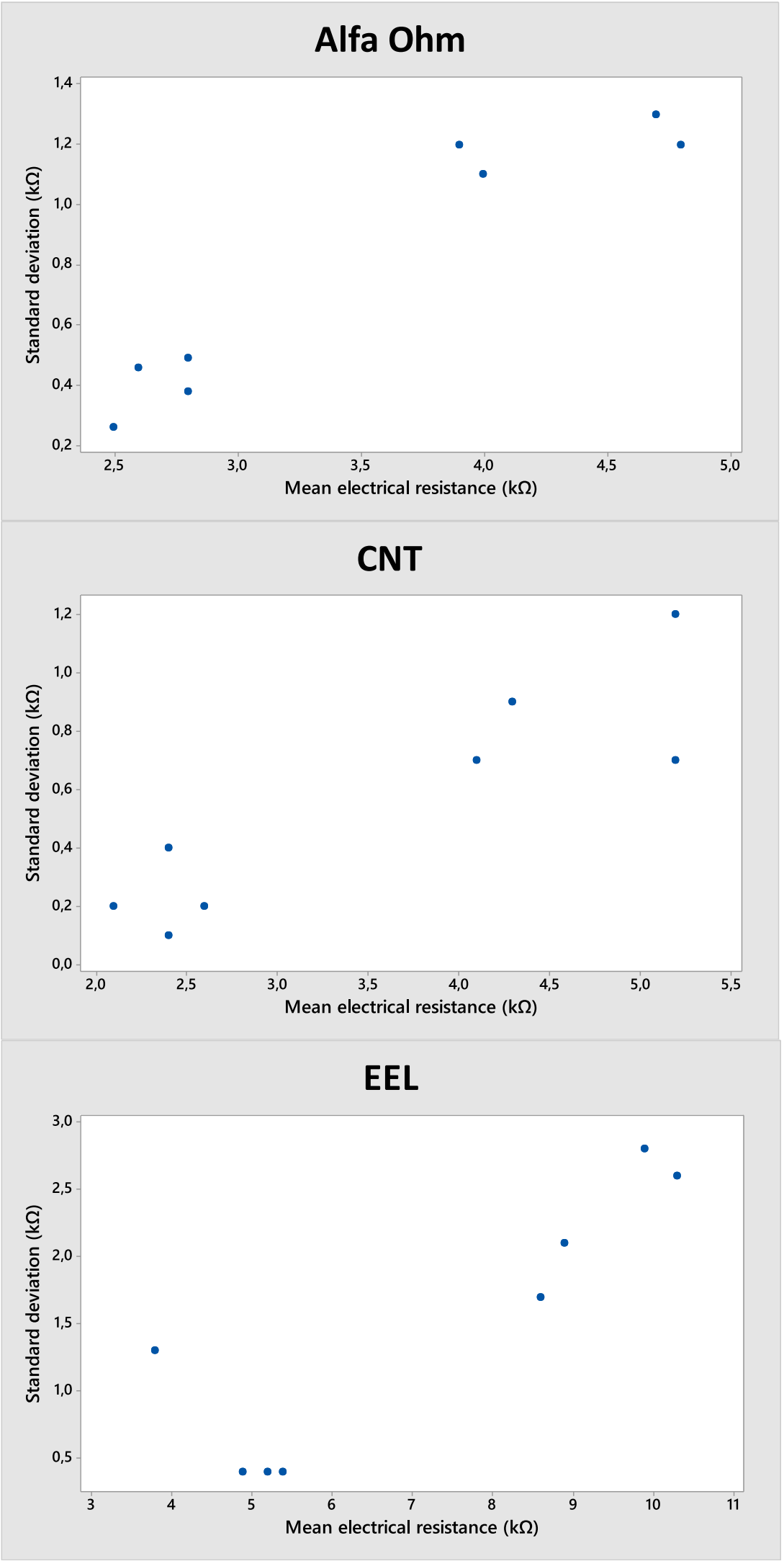




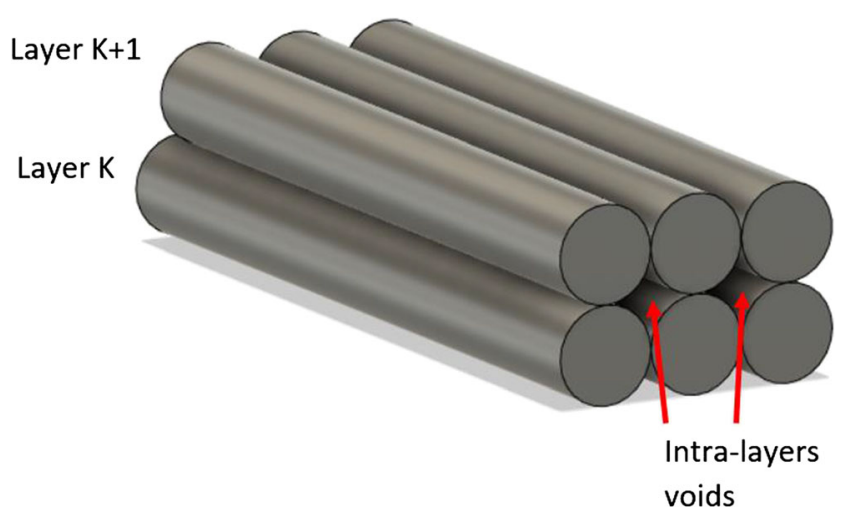

Fig. 5 Simplification of the welding effect to better understand why intralayer voids reduce the electrical resistance. In real cases, the intra-layer voids are smaller than in this design because the extruded filaments are not perfectly cylindrical, but have a quasi-elliptical shape

rows of Section 2.2, the link between the layer height and number of layers is explained) from 5 to 3 (using a parallel printing orientation), so the total number of intralayer voids decreases.

For this reason, the printing orientation is the process parameter with the second major effect for all conductive materials: when switching from a low level (parallel strain gauge orientation) to a high level (perpendicular strain gauge orientation), the electrical resistance meaningfully increases, because, for a low level, the number of layers to build is less than that required for a high level.

The "welding effect" also explains why the interaction between the layer height and printing orientation causes a relevant effect in AlfaOhm and CNT (produces the third significant effect), while in Eel, this effect is marginal, but this is probably due to the anomalous resistance value found in the combination $a b$.

In conclusion, the resistance minimization (and variability minimization) depends on the "welding effect," which is minimized when the number of layers is reduced. The printing parameters accountable for the reduction of the layer number are the layer height (factor A) and printing orientation (factor $\mathrm{C}$ ), so it seems clear that the optimization of these two parameters (and their interaction) leads to resistance and variability minimization:

3) The effect of the parameter B, namely, the line width, is not significant; indeed, voids among the extruded filaments along the same layer are very few in number and slightly affect the electrical resistance (when switching from a low to high level, the resistance increase is low). Additionally, the other parameter combinations $\left(\mathrm{A}^{*} \mathrm{~B}\right.$, $\mathrm{B}^{*} \mathrm{C}$, and $\mathrm{A}^{*} \mathrm{~B}{ }^{*} \mathrm{C}$ ) do not involve significant effects in terms of resistance minimization and variability reduction.

4) The best printing parameter combination which minimizes the electrical resistance and the variability in 3Dprinted strain gauges for each conductive material is the combination $a b$, characterized by high levels of layer height and line width and a low level of printing orientation. Then, the process parameters set to minimize the electrical resistance and variability are a layer height equal to $0.3 \mathrm{~mm}$, line width of $0.5 \mathrm{~mm}$, and "parallel" printing orientation; with this process configuration, 2.5 , 2.133 , and $3.8 \mathrm{k} \Omega$ were the mean electrical resistance values obtained for AlfaOhm, CNT, and Eel, respectively.

\subsection{Design parameter investigation}

In this section, two design parameters are investigated to understand how they affect the final electrical resistance and if a correlation between them and variability exists. The printing parameters used for each conductive material in this phase were the best ones found in Section 2.2: printing parameters in accordance with the combination $a b$ (layer height $=0.3 \mathrm{~mm}$, line width $=$ $0.5 \mathrm{~mm}$, and printing orientation = parallel) were set. The design parameters varied in this study are the number of tracks and active length (see Fig. 6) named D and E, respectively. The low $(-1)$ and high $(+1)$ levels of $\mathrm{D}$ are 4 and 6, while for E, they are $9 \mathrm{~mm}$ and $15 \mathrm{~mm}$. Other design parameters were kept unchanged; in particular, the distance between two adjacent tracks was $1 \mathrm{~mm}$, the size of the pads (needed to weld electric wires) was $5 \mathrm{~mm} * 6 \mathrm{~mm}$, and the end loops (needed to reduce transverse effects due to deformations when weights are applied) were $3 \mathrm{~mm} * 4 \mathrm{~mm}$. All dimensions mentioned above refer to the $x-y$ plane, while the height of the strain gauge was $1 \mathrm{~mm}$.

Then, a factorial plan $2^{2}$ with three replications was run. In Table 7, Table 8, and Table 9, the results for the three

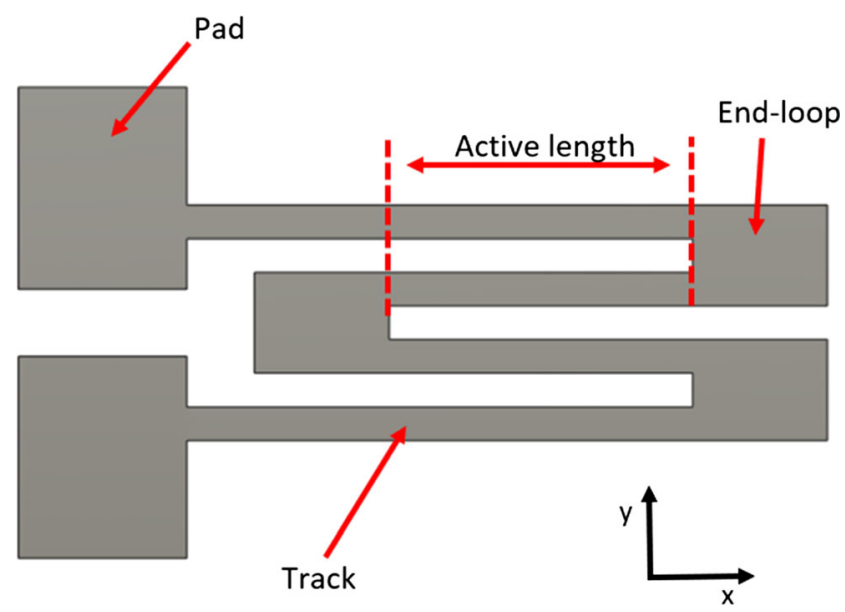

Fig. 6 Strain gauge design 
Table 7 AlfaOhm design parameter factorial plan

AlfaOhm

\begin{tabular}{|c|c|c|c|c|c|c|c|}
\hline \multirow[t]{2}{*}{ Combination } & \multirow[t]{2}{*}{$\mathrm{D}$} & \multirow[t]{2}{*}{$\mathrm{E}$} & \multicolumn{3}{|c|}{ Replication $(k \Omega)$} & \multirow{2}{*}{$\begin{array}{l}\mu \\
(k \Omega)\end{array}$} & \multirow{2}{*}{$\begin{array}{l}\sigma \\
(k \Omega)\end{array}$} \\
\hline & & & $n_{1}$ & $n_{2}$ & $n_{3}$ & & \\
\hline$f$ & -1 & -1 & 2.8 & 2.4 & 2.3 & 2.5 & 0.3 \\
\hline g & +1 & -1 & 4.8 & 4.2 & 4.8 & 4.6 & 0.3 \\
\hline $\mathrm{h}$ & -1 & +1 & 4.4 & 4.7 & 4.6 & 4.6 & 0.2 \\
\hline $\mathrm{i}$ & +1 & +1 & 6.6 & 7.3 & 6.5 & 6.8 & 0.4 \\
\hline
\end{tabular}

conductive materials are reported, while in Fig. 7, Pareto charts of the standardized effects are shown.

The three samples of combination $f$ of each analyzed conductive material were not been manufactured again, because they had already been printed during the printing parameter investigation: the $a b$ combination of printing parameters is the same as the $f$ combination. Hence, for combination $f$, the same data achieved for combination $a b$ were used.

From the data analysis of factorial plans, the following considerations stand out:

1) Unlike the previous investigation, in this case, there was no correlation among resistance minimization and variability minimization. The standard deviation for each combination of each conductive material was always less than $0.51 \mathrm{k} \Omega$, except for the combination $f$ of Eel, but this anomalous behavior, as explained in Section 2.2, can be explained by a cross-contamination problem. It is thus possible to affirm that the variability among strain gauges is only related to printing parameters and, in particular, to the "welding effect."

2) Parameters D and E, as shown in Fig. 7, produce significant effects in terms of the final electrical resistance. When increasing the number of tracks (factor D) from 4 (low level) to 6 (high level), the electrical resistance of the strain gauge increases almost equally in comparison to increasing the active length (factor E) from 9 to $15 \mathrm{~mm}$.

Table 8 CNT design parameter factorial plan

\begin{tabular}{lllllllll}
\hline $\mathrm{CNT}$ & & & & & & & \\
\hline Combination & $\mathrm{D}$ & $\mathrm{E}$ & \multicolumn{2}{l}{ Replication $(k \Omega)$} & $\begin{array}{l}\mu \\
(k \Omega)\end{array}$ & $\begin{array}{l}\sigma \\
(k \Omega)\end{array}$ \\
\cline { 3 - 6 } & & & $n_{1}$ & $n_{2}$ & $n_{3}$ & & \\
\hline $\mathrm{f}$ & -1 & -1 & 1.9 & 2.2 & 2.3 & 2.1 & 0.2 \\
$\mathrm{~g}$ & +1 & -1 & 4.3 & 4.2 & 4.5 & 4.3 & 0.2 \\
$\mathrm{~h}$ & -1 & +1 & 4.3 & 4.0 & 4.4 & 4.2 & 0.2 \\
$\mathrm{i}$ & +1 & +1 & 6.5 & 6.2 & 6.6 & 6.4 & 0.2 \\
\hline
\end{tabular}

Table 9 Eel design parameter factorial plan

\begin{tabular}{|c|c|c|c|c|c|c|c|}
\hline \multirow[t]{2}{*}{ Combination } & \multirow[t]{2}{*}{$\mathrm{D}$} & \multirow[t]{2}{*}{$\mathrm{E}$} & \multicolumn{3}{|c|}{ Replication $(k \Omega)$} & \multirow{2}{*}{$\begin{array}{l}\mu \\
(k \Omega)\end{array}$} & \multirow{2}{*}{$\begin{array}{l}\sigma \\
(k \Omega\end{array}$} \\
\hline & & & $n_{1}$ & $n_{2}$ & $n_{3}$ & & \\
\hline $\mathrm{f}$ & -1 & -1 & 4.8 & 4.3 & 2.4 & 3.8 & 1.3 \\
\hline $\mathrm{g}$ & +1 & -1 & 6.7 & 6.5 & 7.2 & 6.8 & 0.4 \\
\hline $\mathrm{h}$ & -1 & +1 & 6.0 & 7.0 & 6.4 & 6.5 & 0.5 \\
\hline $\mathrm{i}$ & +1 & +1 & 10.2 & 9.2 & 9.5 & 9.6 & 0.5 \\
\hline
\end{tabular}

The effect of the two design parameters analyzed in this study is very similar for all the conductive materials; to be truthful, the effect of the number of tracks is slightly more significant than that of the active length. If we increase the number of tracks and the active length, then the resistance of the strain gauges also increases, as expected, because the term $l$ of Eq. (3), which describes the electrical resistance law, is increased, while the other two terms ( $A$ and $\rho$ ) are left unchanged.

$R=\rho \frac{l}{A}$

where $R$ is the electrical resistance, $\rho$ is the material resistivity, $l$ is the conductive material length, and $A$ is the transverse section of conductive material.

3) The effect of the interaction between the two design parameters does not involve any significant effect in terms of resistance minimization.

For the convenience of the reader, Table 10 and Table 11 summarize the outputs of the whole DoE in terms of the best parameters (printing and design) found and respective values of electrical resistance for each conductive filament.

\section{Thermal characterization}

After the optimization of printing and design parameters, further preliminary experiments were performed to characterize the sensitivity of each specimen to thermal stresses, highlighting an important property. Indeed, the prototype is sensitive not only to mechanical stress but also to thermal ones. The lack of scientific literature about thermal properties of this innovative class of composite materials used for the printed specimens led us to study the effects of temperature variation on resistance. From the study reported here, a positive 

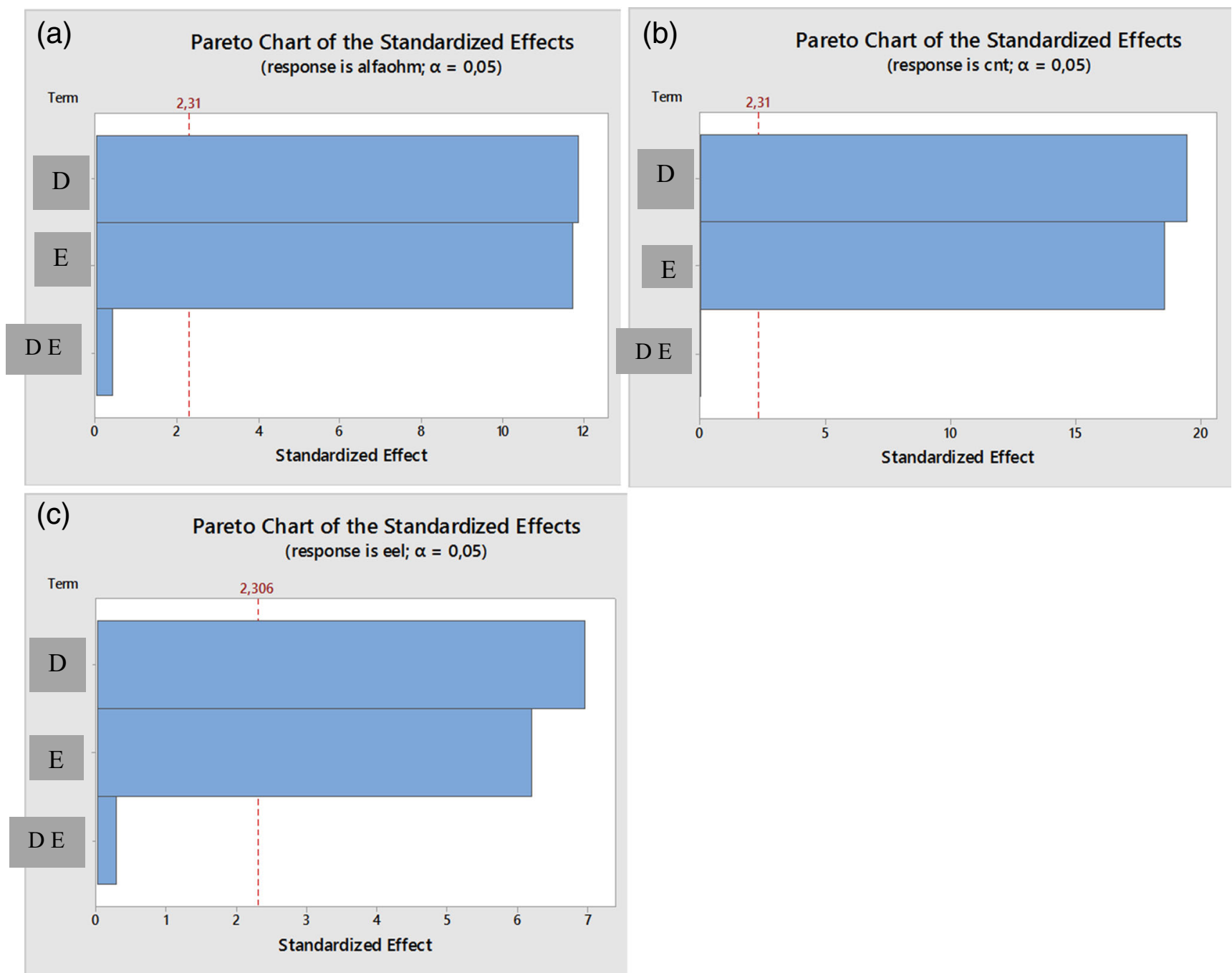

Fig. 7 Pareto charts of standardized effects: (a) AlfaOhm, (b) CNT, and (c) Eel

correlation between the electrical resistance and temperature was observed. Figure 8 shows the behavior of resistance values of CNT specimens obtained by varying the ambient temperature in a time range of about $156 \mathrm{~min}$. In this section, we describe a set of preliminary experimental tests, thus paving the way for a first thermal characterization of these materials.

\subsection{Experimental setup}

A first set of experiments was conducted on four specimens of two conductive materials, i.e., two CNT and two Eel materials. In particular, R1 and R2 of Table 11 were considered for both CNT and Eel materials. We chose to examine the R1 specimen of Eel, although its resistance significantly differs from the mean resistance, because it could highlight interesting aspects. The experimental setup consists of the following: i. Four GDM-8351 digital multimeters (Good Will Instruments Co., LTD), for accurate measurements of the electrical resistance

ii. Two DS18B20 digital temperature sensors

iii. An Arduino Nano board to acquire data from the temperature sensors

Table 10 Best printing and design parameters

\begin{tabular}{ll}
\hline Parameter & Value \\
\hline Layer height & $0.3 \mathrm{~mm}$ \\
Line width & $0.5 \mathrm{~mm}$ \\
Printing orientation & parallel \\
Number of tracks & 4 \\
Active length & $9 \mathrm{~mm}$ \\
\hline
\end{tabular}


Table 11 Electrical resistance related to the best set of printing and design parameters at $22.5^{\circ} \mathrm{C}$

Resistance $(\mathrm{k} \Omega)$

\begin{tabular}{llll}
\hline $\begin{array}{l}\text { Material } \\
\text { Specimen }\end{array}$ & AlfaOhm & CNT & Eel \\
\hline R1 & 2.8 & 1.9 & 2.4 \\
R2 & 2.4 & 2.2 & 4.8 \\
R3 & 2.3 & 2.3 & 4.3 \\
Mean & 2.5 & 2.1 & 3.8 \\
Standard deviation & 0.26 & 0.21 & $1.3 *$ \\
\hline
\end{tabular}

*See Section 2.2, point 1)

iv. A Roboze One 3D printer, whose build plate can be heated up to $100{ }^{\circ} \mathrm{C}$ and used to control temperature variations

v. A control program developed in LabVIEW® (by National Instruments Corp.), which allows the measurement system to be easily managed and controlled, providing realtime information about the system's state and the storage of data for post-processing

The four specimens were placed on a flat support made of polylactic acid (PLA), as shown in Fig. 9, so that they were not in direct contact with the plate of the $3 \mathrm{D}$ printer. Moreover, they were enclosed in a plastic box that created a sort of climatic chamber inside (Fig. 10), in order to reduce the

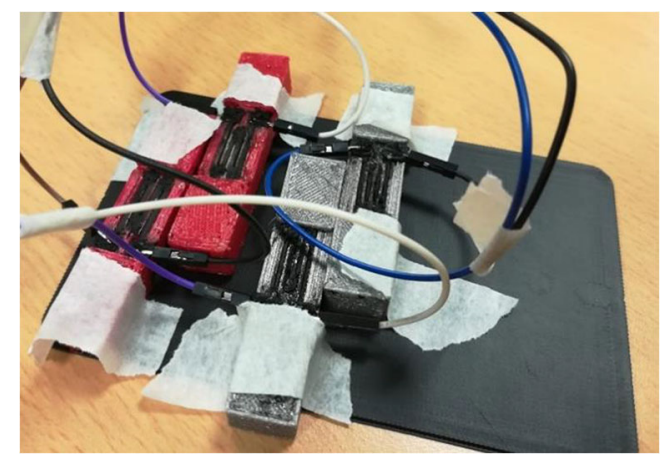

Fig. 9 Arrangement of CNT (red) and Eel (gray) specimens

temperature gradients. The temperature inside the box was measured by means of the two temperature sensors, one positioned near the plate and the other at the top, in order to identify possible temperature gradients. The multimeters were used to measure the resistance of each specimen, and a control program was developed for data acquisition.

\subsection{Experimental tests and results}

The temperature of the build plate was changed in a range of $25-50{ }^{\circ} \mathrm{C}$, with an increment of $5{ }^{\circ} \mathrm{C}$, for a total of six steps. For each step, a settling time was considered to assure a stable temperature inside the plastic box, within a fixed tolerance. Finally, the plastic box was placed outside the $3 \mathrm{D}$ printer, for a faster cooling down process. Obviously, the temperature inside the box was different form the temperature of the plate; in fact, the temperature inside the box only varied from about
Fig. 8 Resistance and temperature vs. time of CNT specimens, without stress
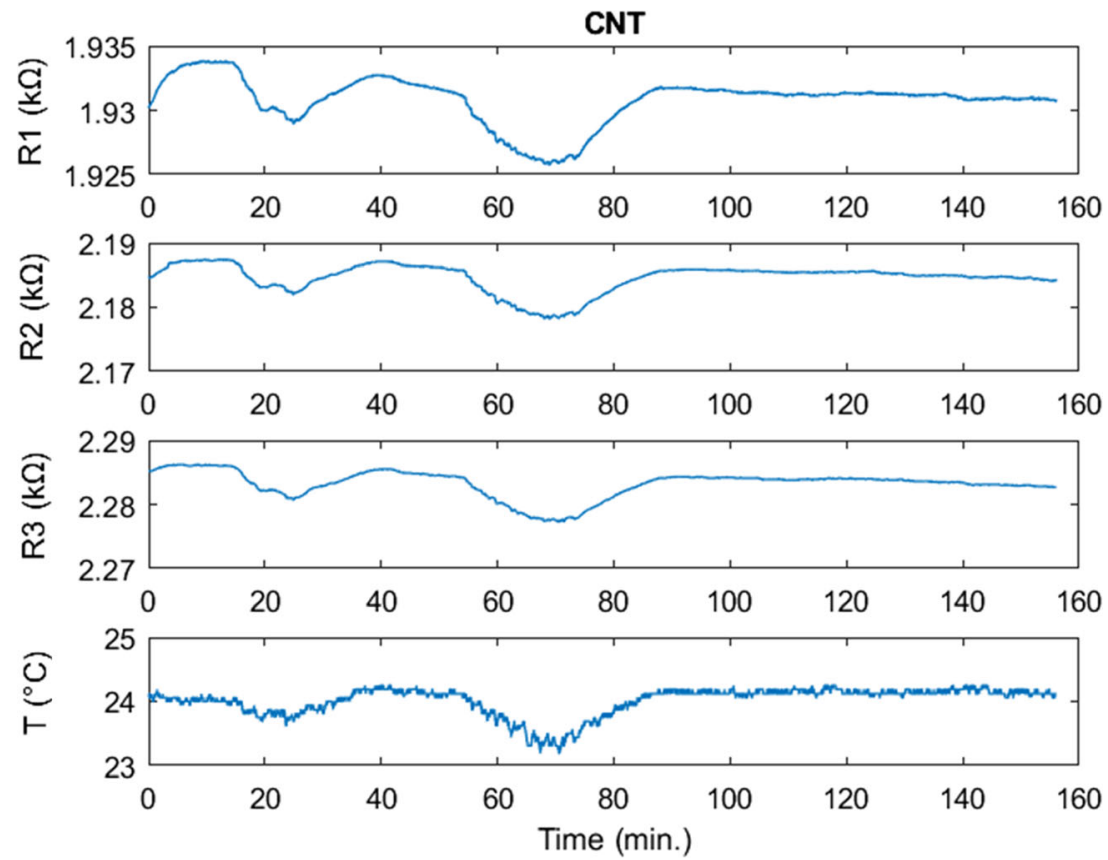


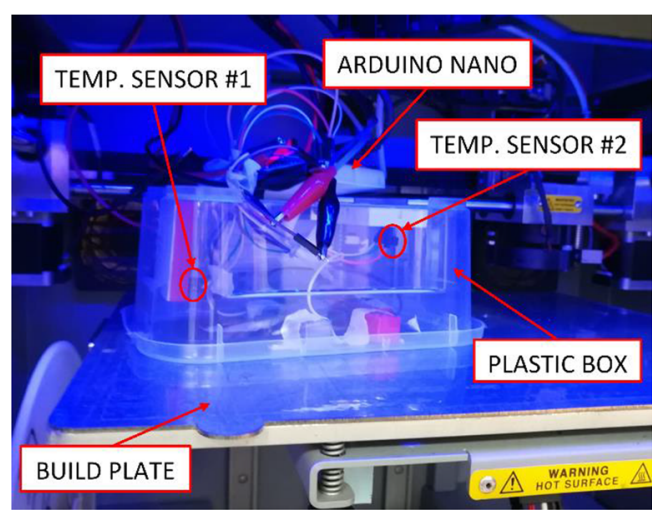

Fig. 10 DIY climatic chamber

$18-34{ }^{\circ} \mathrm{C}$. A temperature difference below about $0.5{ }^{\circ} \mathrm{C}$ was observed between the two sensors in stationary or varying temperature tests, which was partly due to the temperature gradients and partly due to the sensor accuracy. Indeed, since the sensor accuracy is $0.5{ }^{\circ} \mathrm{C}$, temperature differences up to $1{ }^{\circ} \mathrm{C}$ constitute compatible measurements. For these reasons, the mean of the temperature measured with the two sensors was considered.

Figure 11 shows the behavior of the measured resistance of each specimen and the mean temperature during the experimental test. To reduce the effect of noise and quantization of the temperature measurement, a moving average of 21 samples was employed.

A positive correlation between the resistance of each specimen and the temperature could be observed. Each time the plate temperature was incremented in steps, the sensor value and resistance increase reached a steady state after a few minutes; this confirms the positive temperature coefficient (PTC) of these composite materials. The small step decreases at about 230 min originated when the plastic box was placed outside the 3D printer in the final part of the experiment.

To investigate the relationship between resistance and temperature, the behavior of the resistance of each specimen versus temperature was analyzed as shown in Fig. 12. The presence of hysteresis in the R2 specimen of Eel can be observed. Moreover, all four specimens exhibit a high linearity in the considered temperature range. Hence, linear regression was performed, and an estimation of the temperature coefficient (TC) $\alpha_{T}$ of each material was obtained as

$\alpha_{T}=\frac{R-R_{0}}{R_{0}\left(T-T_{0}\right)}\left({ }^{\circ} \mathrm{C}^{-1}\right)$,

where $R$ is the resistance at temperature $T, R_{0}$ is the resistance at a reference temperature $T_{0}$, and $\alpha_{T}$ depends on the reference temperature considered.

Both specimens of CNT present a TC of about 0.011 ${ }^{\circ} \mathrm{C}^{-1}$ at $T_{0}=20^{\circ} \mathrm{C}$, whereas the two Eel specimens present a $\alpha_{T}$ of about $0.007^{\circ} \mathrm{C}^{-1}$ at $T_{0}=20^{\circ} \mathrm{C}$. These values are quite high for a temperature coefficient, compared with typical values of Platinum resistance temperature sensors (RTD), which are about $0.0039^{\circ} \mathrm{C}^{-1}$ [38]. Moreover, the TC of CNT is of the same order of magnitude as those of commercial negative TC thermistors, which generally present a high TC from about -0.02 to $-0.04 \frac{1}{{ }^{\circ} \mathrm{C}}$ at room temperature [39]. Therefore, also considering the high linearity of the materials, the obtained results suggest that these materials could be exploited to realize temperature sensors.

It is not easy to interpret these results from a chemical perspective. It should be noted that resistivity of conductive
Fig. 11 Resistance of the specimens and temperature vs. time
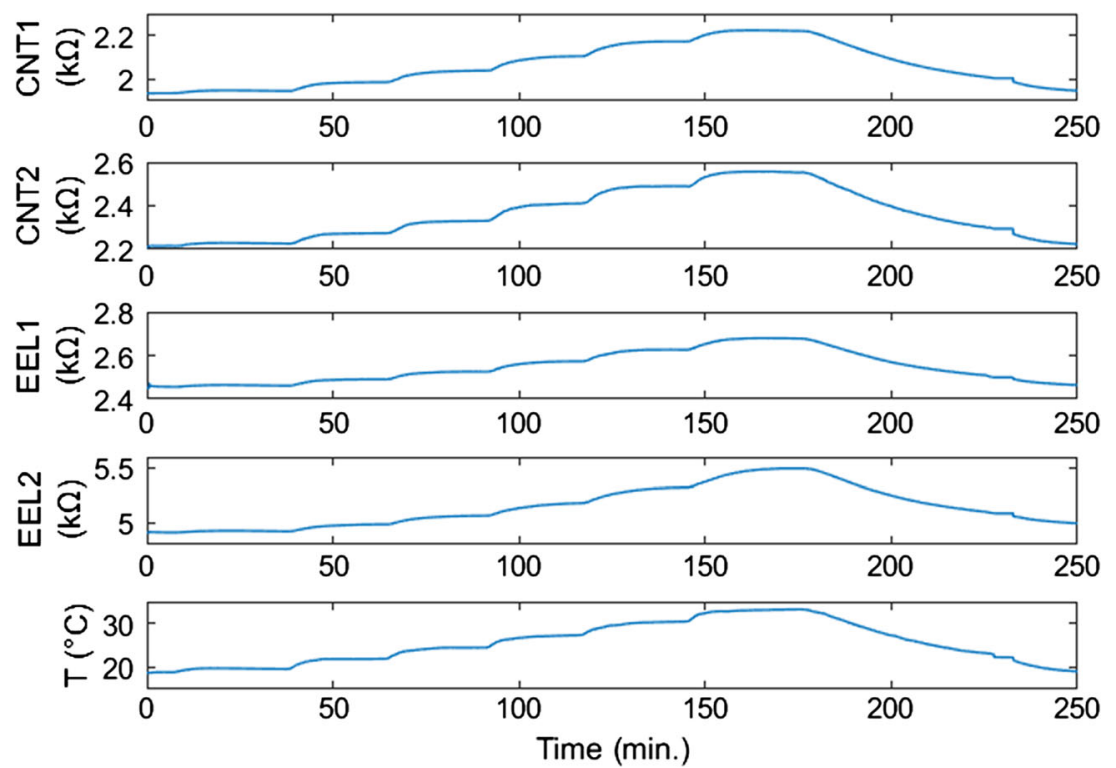
Fig. 12 Resistance of each specimen vs. temperature
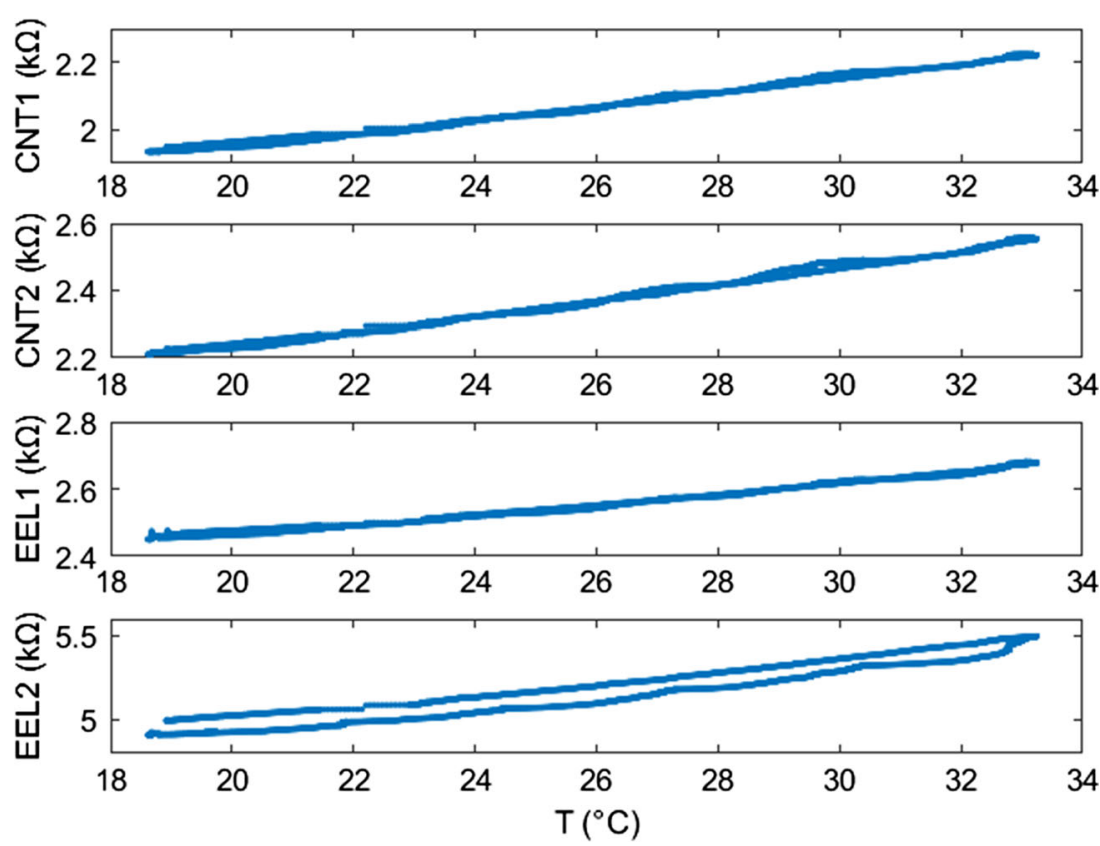

polymer composites filled with carbon (carbon black, carbon fibers, graphene or CNTs) varies greatly according to the different combinations and concentrations of polymer matrices, fillers, deposition, and operation temperatures, and the outcome is not easily predictable [40]. Moreover, the precise composition of the deposed material, being a trade secret, may be unknown. Hence it is important to characterize experimentally these materials. It is believed that the main conduction mechanisms are electron hopping and electron tunneling, which lead both to a decrease of resistivity with temperature increase (negative TC); however a competing phenomenon at higher temperatures, namely, the increased size of intra-bead air voids, may lead to an increase of resistivity (positive TC) [41]. It can be speculated that the results reported here (positive TC) refer to a temperature range that is, for both the examined materials, above the temperature split point between negative and positive TC.

The observed positive TC of TPU doped with carbon black is somewhat comparable with the one reported in [42] for a different polymer, namely, a printed wire of PLA doped with carbon black, which exhibited a positive TC of $0.0284 \frac{1}{{ }^{\circ} \mathrm{C}}$ for temperature ramp up and $0.0242 \frac{1}{{ }^{\circ} \mathrm{C}}$ for temperature ramp down.

The observed positive TC for PLA doped with CNTs, instead, is in contrast with several works on polymer matrices (polyurethane [43], PEEK [44]) doped with CNTs, where a negative TC was reported. However, a split point at about $40{ }^{\circ} \mathrm{C}$ between negative TC and positive TC was observed in [42] for blocks printed with a graphene-PLA filament. Finally, in [41] split points between about $-75^{\circ} \mathrm{C}$ and $0{ }^{\circ} \mathrm{C}$ were observed for different concentrations of short carbon fibers in ultra-high molecular weight polyethylene, which is compatible with the results reported here.

\section{Conclusion}

In conclusion, a design of experiment (DoE) has been performed on three different conductive commercial materials to understand how two types of parameters (printing and design parameters) affect the electrical resistance and variability in strain gauges manufactured via fused filament fabrication (FFF), which is the most common and inexpensive 3D printing technology. The following conclusions can be drawn:

- Printing parameters affect the electrical resistance and variability. In particular, from the printing parameter investigation, it could be seen that there is a positive correlation among electrical resistance and variability; indeed, with optimized printing parameters, it was possible to minimize both.

- Layer height is the main printing parameters affecting electrical resistance and variability: switching from low value $(0.2 \mathrm{~mm})$ to high value $(0.3 \mathrm{~mm})$, a great decrease of electrical resistance and variability occurs. The printing orientation parameter and the interaction among the latter and layer height cause the second and third most important effects. The authors address this behavior to welding effect (explained in 2.2 and shown in Fig. 5) which reduces the adhesion among subsequent layers made by conductive material, generating intra-layer voids, and for this 
reason, an increase in electrical resistance and variability occurs.

- Design parameters affect only electrical resistance and not variability. From their investigation, expected results were achieved: when the number of tracks and the active length of strain gauges increase, then the electrical resistance also increases.

- Regardless of the conductive material used, the best results in terms of resistance and variation minimization are achieved with the following configuration: layer height = $0.3 \mathrm{~mm}$; line width $=0.5 \mathrm{~mm}$; printing orientation $=$ parallel; number of tracks $=4$; and active length $=9 \mathrm{~mm}$.

- A thermal analysis on 3D-printed samples was carried out: the temperature coefficient of resistance was preliminarily measured in a $16{ }^{\circ} \mathrm{C}$ temperature range for four samples, obtaining values between 0.007 and $0.011^{\circ} \mathrm{C}^{-1}$ at $T_{0}=$ $20{ }^{\circ} \mathrm{C}$. Obviously, further work will consider the thermal characterization of these materials in a larger temperature range by using an industrial climatic chamber and a suitable standardized test protocol. Since the resistance of produced samples changes with the applied strain, as preliminarily shown by tests not reported here, a challenge and opportunity will be to discriminate between mechanical and thermal stresses. This has been done, for example, with optic fiber sensors, where distributed measurements of strain and temperature can be performed simultaneously. The fabrication and the characterization of a 3Dprinted load cell, which adopts a Wheatstone bridge configuration aimed at reducing thermal effects and measuring only applied forces, was presented by the authors in [29].

This work lays the foundation for further analysis to more deeply characterize these recent materials and their printing processes, which could find application as smart materials with temperature, force, and pressure sensing capabilities in a wide range of fields, from wearable sensors to medical devices and soft robotics.

Funding Open access funding provided by Politecnico di Bari within the CRUI-CARE Agreement.

Data availability Not applicable.

\section{Compliance with ethical standards}

Conflict of interest The authors declare no conflict of interests.

Code availability Not applicable.

Open Access This article is licensed under a Creative Commons Attribution 4.0 International License, which permits use, sharing, adaptation, distribution and reproduction in any medium or format, as long as you give appropriate credit to the original author(s) and the source, provide a link to the Creative Commons licence, and indicate if changes were made. The images or other third party material in this article are included in the article's Creative Commons licence, unless indicated otherwise in a credit line to the material. If material is not included in the article's Creative Commons licence and your intended use is not permitted by statutory regulation or exceeds the permitted use, you will need to obtain permission directly from the copyright holder. To view a copy of this licence, visit http://creativecommons.org/licenses/by/4.0/.

\section{References}

1. Yusuf SM, Cutler S, Gao N (2019) Review: The impact of metal additive manufacturing on the aerospace industry. Metals 9(12): 1286. https://doi.org/10.3390/met9121286

2. Singamneni S, Lv Y, Hewitt A, Chalk R, Thomas W, Jordison D (2019) Additive manufacturing for the aircraft industry : a review journal of aeronautics \& aerospace additive manufacturing for the aircraft industry : a review. J Aeronaut Aerosp Eng. 8(March):0-13. https://doi.org/10.4172/2329-6542.1000214

3. Calleja A, Tabernero I, Ealo JA et al (2014) Feed rate calculation algorithm for the homogeneous material deposition of blisk blades by 5-axis laser cladding. Int J Adv Manuf Technol 74:1219-1228. https://doi.org/10.1007/s00170-014-6057-3

4. Norberto L (2019) A methodology to evaluate the reliability impact of manufacturing spare parts, pp 1-19

5. Zindani D, Kumar K (2019) An insight into additive manufacturing of fiber reinforced polymer composite. Int J Light Mater Manuf 2(4):267-278. https://doi.org/10.1016/j.ijlmm.2019.08.004

6. Li Y, Yu S, Chen Y, Yu R, Shi Y (2020) Wire and arc additive manufacturing of aluminum alloy lattice structure. J Manuf Process 50(December 2019):510-519. https://doi.org/10.1016/j.jmapro. 2019.12.049

7. Yao X, Luan C, Zhang D, Lan L, Fu J (Jan. 2017) Evaluation of carbon fiber-embedded 3D printed structures for strengthening and structural-health monitoring. Mater Des 114:424-432. https://doi. org/10.1016/j.matdes.2016.10.078

8. Cataldo A, De Benedetto E, Cannazza G, Piuzzi E, Giaquinto N (May 2015) Embedded TDR wire-like sensing elements for monitoring applications. Meas J Int Meas Confed 68:236-245. https:// doi.org/10.1016/j.measurement.2015.02.050

9. Lehmhus D, Aumund-Kopp C, Petzoldt F, Godlinski D, Haberkorn A, Zöllmer V, Busse M (2016) Customized smartness: a survey on links between additive manufacturing and sensor integration. Procedia Technol 26:284-301. https://doi.org/10.1016/j.protcy. 2016.08.038

10. Tan HW, Tran T, Chua CK (2016) A review of printed passive electronic components through fully additive manufacturing methods. Virtual Phys Prototyp 11(4):271-288. https://doi.org/10. 1080/17452759.2016.1217586

11. Saengchairat N, Tran T, Chua CK (2017) A review: additive manufacturing for active electronic components. Virtual Phys Prototyp. 12(1):31-46. https://doi.org/10.1080/17452759.2016. 1253181

12. You J, Preen RJ, Bull L, Greenman J, Ieropoulos I (2017) 3D printed components of microbial fuel cells: towards monolithic microbial fuel cell fabrication using additive layer manufacturing. Sustain Energy Technol Assessments 19:94-101. https://doi.org/ 10.1016/j.seta.2016.11.006

13. MacDonald E, Wicker R (2016) Multiprocess 3D printing for increasing component functionality. Science 353(6307):aaf2093. https://doi.org/10.1126/science.aaf2093

14. Emon MOF, Alkadi F, Philip DG, Kim DH, Lee KC, Choi JW (2019) Multi-material 3D printing of a soft pressure sensor. Addit 
Manuf. 28(May):629-638. https://doi.org/10.1016/j.addma.2019. 06.001

15. Espera AH, Dizon JRC, Chen Q, Advincula RC (2019) 3D-printing and advanced manufacturing for electronics. Prog Addit Manuf 4(3):245-267. https://doi.org/10.1007/s40964-019-00077-7

16. Dijkshoorn A, Werkman P, Welleweerd M, Wolterink G, Eijking B, Delamare J, Sanders R, Krijnen GJM (2018) Embedded sensing: integrating sensors in 3-D printed structures. J Sensors Sens Syst 7(1):169-181. https://doi.org/10.5194/jsss-7-169-2018

17. MacDonald E et al (2014) 3D printing for the rapid prototyping of structural electronics. IEEE Access 2(December):234-242. https:// doi.org/10.1109/ACCESS.2014.2311810

18. Espalin D, Muse DW, MacDonald E, Wicker RB (2014) 3D printing multifunctionality: structures with electronics. Int J Adv Manuf Technol 72(5-8):963-978. https://doi.org/10.1007/s00170-0145717-7

19. Kim C, Espalin D, Liang M, Xin H, Cuaron A, Varela I, Macdonald E, Wicker RB (2017) 3D printed electronics with high performance, multi-layered electrical interconnect. IEEE Access 5:25286-25294. https://doi.org/10.1109/ACCESS.2017.2773571

20. Ni Y, Ji R, Long K, Bu T, Chen K, Zhuang S (2017) A review of 3D-printed sensors. Appl Spectrose Rev 52(7):623-652. https://doi. org/10.1080/05704928.2017.1287082

21. Fiorillo AS, Critello CD, Pullano AS (2018) Theory, technology and applications of piezoresistive sensors: a review. Sensors Actuators A Phys 281:156-175. https://doi.org/10.1016/j.sna. 2018.07.006

22. Amjadi M, Kyung KU, Park I, Sitti M (2016) Stretchable, skinmountable, and wearable strain sensors and their potential applications: a review. Adv Funct Mater 26:1678-1698. https://doi.org/10. 1002/adfm. 201504755

23. Wang J, Liu Y, Su S, Wei J, Rahman S, Ning F, Christopher G, Cong W, Qiu J (2019) Ultrasensitive wearable strain sensors of 3D printing tough and conductive hydrogels. Polymers (Basel) 11(11): 1-15. https://doi.org/10.3390/polym11111873

24. Muth JT, Vogt DM, Truby RL, Mengüç Y, Kolesky DB, Wood RJ, Lewis JA (2014) Embedded 3D printing of strain sensors within highly stretchable elastomers. Adv Mater 26:6307-6312. https:// doi.org/10.1002/adma.201400334

25. Daalkhaijav U, Yirmibesoglu OD, Walker S, Mengüç Y (2018) Rheological modification of liquid metal for additive manufacturing of stretchable electronics. Adv Mater Technol 3(4):1-9. https:// doi.org/10.1002/admt.201700351

26. Mohamed OA, Masood SH, Bhowmik JL (2015) Optimization of fused deposition modeling process parameters : a review of current research and future prospects, pp 42-53. https://doi.org/10.1007/ s40436-014-0097-7

27. Dey A, Yodo N (2019) A systematic survey of FDM process parameter optimization and their influence on part characteristics. J Manuf Mater Process. 3(3):64. https://doi.org/10.3390/ jmmp3030064

28. Galantucci LM, Lavecchia F, Percoco G (2010) CIRP annals manufacturing technology quantitative analysis of a chemical treatment to reduce roughness of parts fabricated using fused deposition modeling. CIRP Ann - Manuf Technol 59(1):247-250. https://doi. org/10.1016/j.cirp.2010.03.074

29. Stano G, Di Nisio A, Lanzolla A, Percoco G (2020) Additive manufacturing and characterization of a load cell with embedded strain gauges. Precis Eng. 62(June 2019):113-120. https://doi.org/ 10.1016/j.precisioneng.2019.11.019

30. Arh M, Slavič J, Boltežar M (2020) Experimental identification of the dynamic piezoresistivity of fused-filament-fabricated structures. Addit Manuf. 36(July):101493. https://doi.org/10.1016/ j.addma.2020.101493

31. Flowers PF, Reyes C, Ye S, Kim MJ, Wiley BJ (2017) 3D printing electronic components and circuits with conductive thermoplastic filament. Addit Manuf 18(2017):156-163. https://doi.org/10.1016/ j.addma.2017.10.002

32. Kim K, Park J, Suh J, Kim M, Jeong Y, Park I (2017) Sensors and actuators a : physical 3D printing of multiaxial force sensors using carbon nanotube ( CNT )/ thermoplastic polyurethane ( TPU ) filaments. Sensors Actuators A Phys 263:493-500. https://doi.org/10. 1016/j.sna.2017.07.020

33. Leigh SJ, Bradley RJ, Purssell CP, Billson DR, Hutchins DA (2012) A simple, low-cost conductive composite material for 3D printing of electronic sensors. PLoS One 7(11):1-6. https://doi.org/ 10.1371/journal.pone.0049365

34. Xiang D et al (2019) Enhanced performance of 3D printed highly elastic strain sensors of carbon nanotube/thermoplastic polyurethane nanocomposites via non-covalent interactions. Compos Part B Eng. 176(July):107250. https://doi.org/10.1016/j.compositesb. 2019.107250

35. Cardenas JA et al (2020) Flash ablation metallization of conductive thermoplastics. Addit Manuf. 36(March):101409. https://doi.org/ 10.1016/j.addma.2020.101409

36. Pretsch T (2010) Review on the functional determinants and durability of shape memory polymers. Polymers (Basel). 2(3):120-158. https://doi.org/10.3390/polym2030120

37. Mitchell A, Lafont U, Hołyńska M, Semprimoschnig C (2018) Additive manufacturing - a review of 4D printing and future applications. Addit. Manuf. 24:606-626. https://doi.org/10.1016/j. addma.2018.10.038

38. Norton HN (1989) Handbook of transducers. Prentice Hall, Englewood Cliffs

39. Luz FCS, Pianaro SA, Yurk CE, Capobianco G, Zara AJ, Tebcherani SM (2014) Construction and testing of a system for the electrical characterization of ceramic thermistors at low temperatures. Ceramica 60(353):96-101. https://doi.org/10.1590/S036669132014000100014

40. Király A, Ronkay F (May 2015) Temperature dependence of electrical properties in conductive polymer composites. Polym Test 43: 154-162. https://doi.org/10.1016/j.polymertesting.2015.03.011

41. Zhang R, Bin Y, Chen R, Matsuo M (Nov. 2013) Evaluation by tunneling effect for the temperature-dependent electric conductivity of polymer-carbon fiber composites with visco-elastic properties. Polym J 45(11):1120-1134. https://doi.org/10.1038/pj.2013.40

42. Daniel F, Patoary NH, Moore AL, Weiss L, Radadia AD (Nov. 2018) Temperature-dependent electrical resistance of conductive polylactic acid filament for fused deposition modeling. Int J Adv Manuf Technol 99(5-8):1215-1224. https://doi.org/10. 1007/s00170-018-2490-Z

43. Zhang R, Dowden A, Deng H, Baxendale M, Peijs T (Aug. 2009) Conductive network formation in the melt of carbon nanotube/ thermoplastic polyurethane composite. Compos Sci Technol 69(10):1499-1504. https://doi.org/10.1016/j.compscitech.2008.11. 039

44. Mohiuddin M, Hoa SV (Dec. 2011) Temperature dependent electrical conductivity of CNT-PEEK composites. Compos Sci Technol 72(1):21-27. https://doi.org/10.1016/j.compscitech.2011.08.018

Publisher's note Springer Nature remains neutral with regard to jurisdictional claims in published maps and institutional affiliations. 